\title{
RELAÇÃO DA RENTABILIDADE E O DISCLOSURE DE PROVISÕES E PASSIVOS CONTINGENTES AMBIENTAIS DAS EMPRESAS DE ALTO POTENCIAL POLUIDOR LISTADAS NA B3
}

\author{
RELATIONSHIP OF PROFITABILITY AND DISCLOSURE OF PROVISIONS AND \\ CONTINGENT LIABILITIES OF HIGH POLLUTION POTENTIAL COMPANIES LISTED \\ ON B3
}

\author{
ANDRÉ FELIPE PEREIRA DA SILVA \\ Universidade Federal da Paraíba. Endereço: Rua Capitão Gomes \\ Duarte, nº 40, Vila Nova Cidade Universitária | 17012-226 / Bauru/SP | \\ Brasil. \\ (1D http://orcid.org/0000-0003-2552-2019 \\ E-mail: andre-fps@hotmail.com
}

RISOLENE ALVES DE MACENA ARAÚJO

Universidade Federal da Paraíba. Endereço: Rua José Paulino Batista, no 103, Cuiá | 58077-142 | João Pessoa/PB / Brasil.

(1) http://orcid.org/0000-0001-9744-2267

E-mail: risolenee@hotmail.com

\section{LÍVIA MARIA DA SILVA SANTOS}

Universidade Federal da Paraíba. Endereço: Rua Josafá Cavalcante de Souza, no 52 | 58079-550 | João Pessoa/PB | Brasil.

(1) http://orcid.org/0000-0001-9839-9424

E-mail: livia.marias@hotmail.com

\section{RESUMO}

Este estudo tem como objetivo analisar a relação entre a rentabilidade e o disclosure de provisões e passivos contingentes ambientais das empresas de alto potencial poluidor listadas na B3. A amostra da pesquisa é formada por 38 empresas de ações negociadas na B3, as

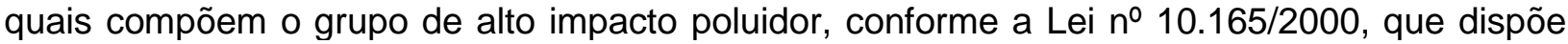
sobre a Política Nacional do Meio Ambiente. Para consecução do objetivo desta pesquisa, utilizou-se a análise de conteúdo para examinar disclosure de provisões e passivos contingentes ambientais pelas empresas, no período de 2011 a 2016, bem como aplicou-se a regressão múltipla de efeito fixo. O resultado apresentou significância estatística entre a variável independente Rentabilidade (RENT) e o disclosure, porém, com um coeficiente negativo, ou seja, as empresas mais rentáveis não são necessariamente aquelas que mais divulgam informações sobre provisões e passivos contingentes ambientais. Tal resultado contraria o argumento de que as empresas mais rentáveis tendem a divulgar mais informações do que aquelas menos rentáveis, justamente para se diferenciar delas. No tocante às demais variáveis, Valor de Mercado e Índice de Sustentabilidade Empresarial (ISE) foram significantes e negativas; Endividamento mostrou-se positiva; Tamanho não apresentou significância; e, por fim, a Governança Corporativa foi omitida do modelo econométrico por se tratar de dummies fixas ao longo do painel. 
Palavras-chave: Disclosure. Provisões e Passivos Contingentes Ambientais. Alto Potencial Poluidor. Rentabilidade.

\section{ABSTRACT}

The present study aims to analyze the relationship between the profitability and the disclosure of environmental contingent provisions and liabilities of the companies with high potential for pollution listed in B3. The research sample consists of 38 companies of shares traded in B3, which makes up the high-impact group, according to Law No. 10,165 / 2000, which deals with the National Environmental Policy. In order to achieve the objective of this research, we used the content analysis to examine the disclosure of environmental contingent provisions and liabilities by companies, in the period from 2011 to 2016, as well as the application of multiple regression of fixed effect. The result presented statistical significance between the independent variable Profitability (RENT) and disclosure, but with a negative coefficient, that is, the most profitable companies are not necessarily the ones that most disclose information on environmental contingent provisions and liabilities. Thus, there was a rejection of the research hypothesis ( $\mathrm{H1}$ : The profitability of companies with high polluting potential is positively related to the disclosure of provisions and contingent environmental liabilities). Such a result runs counter to the argument that most profitable firms tend to disclose more information than less profitable ones, just to differentiate themselves from them. Regarding the other variables, Market Value and Business Sustainability Index (ISE), these were significant and negative, while Indebtedness was positive; Size was not significant, and finally, Corporate Governance was omitted from the econometric model because it was a fixed dummy along the panel.

Keywords: Disclosure. Provisions and Contingent Liabilities. High Pollution Potential. Profitability.

\section{INTRODUÇÃO}

A partir do advento da Revolução Industrial, uma série de problemas começou a afetar o meio ambiente, tornando os recursos naturais escassos e promovendo mudanças climáticas, decorrentes da poluição de rios, do ar e do solo. Com isso, estratégias organizacionais passaram a ser desenvolvidas com o intuito de aliar ações de responsabilidade social, desenvolvimento sustentável, consumo consciente e alcance das metas da empresa (Souza, Rásia, \& Jacques, 2010).

Tais estratégias têm como finalidade obter ganhos de imagem e vantagens financeiras, como a valorização das ações e melhor desempenho econômico-financeiro (Kolk, Levy, \& Pinkse, 2008), visto que a boa imagem ambiental para as organizações, principalmente aquelas de setores de alto risco de acidentes ambientais, tem ganhado importância ao longo do tempo (Nossa, 2002).

Segundo a Lei no 10.165/2000, que trata da Política Nacional do Meio Ambiente, as atividades desenvolvidas pelas entidades são categorizadas conforme o nível de poluição e grau de utilização dos recursos extraídos da natureza, podendo ser de pequeno, médio e alto impacto poluidor (Vieira, Arruda, \& Lima, 2014). Espera-se, portanto, que as organizações de alto impacto poluidor, como forma de se legitimarem perante a sociedade, evidenciem mais informações ambientais do que aquelas que não realizam atividades potencialmente poluidoras (Pereira, Bruni, \& Dias, 2010). Por meio das informações divulgadas, é possível conhecer os riscos e as incertezas inerentes às atividades das organizações e, consequentemente, contribuir para o processo de tomada de decisão dos agentes (Bomfim, Teixeira, \& Monte, 2015).

No Brasil não existe uma lei específica que obrigue as empresas a divulgar informações de caráter socioambiental, entretanto, sua prática se tornou rotina em muitas empresas, principalmente para demonstrar preocupação ambiental e responsabilidade social. Ademais, as informações ambientais podem afetar a situação econômico-financeira das empresas, seja de forma direta ou indireta (Santos, 2016). 
No escopo de informações contábeis de caráter ambiental encontram-se provisões e passivos contingentes ambientais, cuja normatização surgiu com o CPC 25 - Provisões, Passivos Contingentes e Ativos Contingentes, emitido em 2009. Esse pronunciamento define passivos contingentes como uma obrigação presente da entidade, resultante de eventos passados, cuja liquidação se espera que resulte em saída de recursos capazes de gerar benefícios econômicos. Tais obrigações contingenciais estão relacionadas às questões trabalhistas, tributárias, cíveis e ambientais.

De acordo com Bewley (1998), há uma relação positiva entre a divulgação de provisão e passivos contingentes com o valor de mercado das empresas. Todavia, há controvérsias na literatura a respeito da reação do mercado acionário perante a divulgação de informações ambientais nos relatórios financeiros. Por sua vez, Bushman e Smith (2001) complementam que a transparência da informação contábil constitui uma ferramenta importante para que uma empresa se diferencie das demais; sendo assim, provavelmente as provisões e passivos contingentes serão divulgados em suas demonstrações financeiras, se houver ganho econômico.

A esse respeito, duas correntes de pensamento se distinguem. A primeira, denominada como tradicional, defende que as iniciativas tendentes a melhorar a performance ambiental impõem elevados custos às empresas, contribuindo dessa forma para deteriorar sua performance financeira. Contrariamente, a corrente contemporânea defende que aquelas iniciativas contribuem para aumentar a eficiência e melhorar a imagem da empresa em face de seus stakeholders, podendo constituir um fator de diferenciação e competitividade e culminar na melhoria da performance financeira (Roque \& Cortez, 2006).

Já Porter (1991) e Porter e Van Der Linde (1995) apresentam a Hipótese de Porter (HP), a partir da qual argumentam que quando a regulamentação ambiental é bem trabalhada beneficiará tanto o meio ambiente quanto a empresa, pois a preservação ambiental está associada ao aumento da produtividade dos recursos utilizados na produção e, consequentemente, ao aumento da competitividade da empresa. Ademais, Nossa (2002) menciona que os agentes evidenciam ações ambientais da empresa para as partes menos informadas (stakeholders), de maneira a reduzir a assimetria de informação e aumentar a credibilidade da empresa.

Pelo exposto, considerando que as empresas estão sendo pressionadas cada vez mais a demonstrar um desempenho adequado no campo ambiental, configurando-se a responsabilidade social como um dos mecanismos pelos quais elas buscam satisfazer tal exigência, e que a divulgação corporativa de caráter ambiental é um importante meio para a administração influenciar as percepções externas sobre a empresa, visando melhorar seu desempenho econômico, o objetivo deste trabalho é analisar a relação entre a rentabilidade e o disclosure de provisões e passivos contingentes ambientais das empresas de alto potencial poluidor listadas na B3.

Esta pesquisa se justifica pela importância do disclosure de informações ambientais das empresas de alto impacto poluidor, listadas na B3, no que se refere a provisões e passivos contingentes, conforme orienta o CPC 25. Demonstra-se, com isso, a postura das grandes organizações em propiciar aos usuários informações importantes, apresentando seus riscos para o mercado, transmitindo à sociedade, de maneira geral, os riscos implícitos em suas atividades. O estudo justifica-se também pela relevância da temática no contexto da competitividade global entre as empresas, pois o mercado reconhece tais companhias com maior credibilidade, o que estimula o interesse por parte dos investidores (Fernandes, 2013).

Ademais, apesar de haver vários estudos sobre divulgação ambiental voluntária, o contexto que trata de provisões e passivos contingentes ambientais é pouco explorado em pesquisas nacionais. Um dos principais motivos dessa escassez é a não obrigatoriedade de fornecer tais informações; além disso, há cautela dos gestores em prestar informações que ocasionem desconfiança nos stakeholders quanto a investir em empresas com maior propensão de riscos ambientais. 


\section{FUNDAMENTAÇÃO TEÓRICA}

\subsection{Teoria da divulgação discricionária}

O disclosure, ou evidenciação, é a divulgação de informações acerca das entidades que tem como objetivo atender as necessidades dos mais variados tipos de usuários externos das informações contábeis, como também visa o cumprimento da legislação. Existem, ainda, aquelas divulgações discricionárias.

De acordo com Verrecchia (2001), a divulgação discricionária de informações pode ser baseada em três categorias de pesquisa: (1) pesquisa sobre divulgação baseada em associação; (2) pesquisa sobre divulgação baseada em julgamento; e (3) pesquisa sobre divulgação baseada em eficiência. A primeira categoria tem como objetivo investigar os efeitos causados pela divulgação nas ações dos indivíduos, como investidores; a segunda categoria detecta os motivos da divulgação de determinadas informações da entidade; enquanto a terceira e última categoria, segundo o autor, contém pesquisas que discutem quais divulgações são preferíveis na falta de conhecimento prévio sobre alguma informação.

Contribuindo com o exposto, Dye (2001) menciona que não existe uma teoria da divulgação discricionária, a qual o autor classifica como um caso especial da teoria dos jogos, sob a seguinte perspectiva: as entidades apenas divulgarão informações a seu respeito que Ihes forem favoráveis, não tornando públicas aquelas que as desfavoreçam. A teoria dos jogos pressupõe que possam existir determinados resultados, e com base neles os jogadores, neste caso as entidades, escolhem ações premeditadas para melhorar seu retorno, atingindo o objetivo esperado.

Dantas, Zendersky, Santos e Niyama (2005) salientam que se deve achar um equilíbrio entre o custo e o benefício de divulgar informações, não devendo as desvantagens ser maiores que as vantagens. Dessa forma, uma entidade que demonstre resultados satisfatórios nos contextos socioeconômico e ambiental, ou que se avalie capaz de alcançá-los, terá mais estímulo para divulgar voluntariamente as informações, pois entenderá que as vantagens compensarão os custos.

Todavia, para uma entidade que pressupõe maus desempenhos, a não evidenciação pode ser mais prudente; do contrário, a empresa pode prejudicar tanto sua reputação quanto a de seu administrador (Dantas et al., 2005). Verrecchia (2001) destaca que, em um contexto de inexistência de custos com divulgação, as entidades precisam expor as informações de forma voluntária, pois a não divulgação pode ser mal vista pelo mercado.

De qualquer modo, à medida que mais informações forem divulgadas pelas entidades, menos informações serão exclusivas e, portanto, privilegiadas. Assim os gestores terão suas chances reduzidas de obter benefícios próprios por deter esse conhecimento. Uyar e Kiliç (2012) afirmam que quanto mais informações discricionárias forem divulgadas pelas empresas, maior será a compreensão dos usuários quanto ao seu valor.

\subsection{Provisões e passivos contingentes ambientais}

De acordo com as normas contábeis brasileiras, a publicação de informações de natureza ambiental não é obrigatória. No entanto, existem recomendações para a divulgação das provisões, contingências passivas e ativas aplicáveis às questões ambientais, editadas a partir da Deliberação da CVM no 594, de 15 de setembro de 2009, a qual torna obrigatória a aplicação do CPC 25 pelas companhias abertas, a partir do exercício financeiro de 2010 (Martins, Gelbcke, Santos, \& ludícibus, 2013).

O pronunciamento CPC 25 requer a divulgação de informações tanto quantitativas quanto qualitativas acerca das provisões e contingências (Baldoino \& Borba, 2015). Sobre isso, Dantas et al. (2005) notam certa similaridade entre a abrangência do disclosure e a definição de transparência; no entanto, ressaltam que o conceito de evidenciação vai além do simples ato de divulgar, abrangendo também outros fatores, como qualidade, oportunidade e clareza, o que permite aos usuários avaliar aspectos empresariais, como a condição financeira, o desempenho nos negócios, etc.

Diante disso, a divulgação do passivo contingente nas demonstrações contábeis e nas notas explicativas torna-se essencial para que os usuários obtenham a informação útil e 
confiável, auxiliando-os na tomada de decisão (Caetano, Silva, Biesdorf, \& Leal, 2010). Para tanto, o CPC 25 visa garantir que seus critérios de reconhecimento e mensuração sejam usados adequadamente, bem como garantir informações claras em notas explicativas que possibilitem àqueles que as utilizam a compreensão da natureza, oportunidade e valor dos elementos (Oliveira, Benetti, \& Varela, 2011).

Em geral, todas as provisões são contingentes porque são incertas quanto ao prazo ou valor. Porém, o CPC 25 esclarece que o termo "contingente" é usado para passivos e ativos que não sejam reconhecidos porque sua existência somente será confirmada pela ocorrência ou não de um ou mais eventos futuros incertos, não totalmente sob controle da entidade. Adicionalmente, o termo passivo contingente é usado para passivos que não satisfaçam os critérios de reconhecimento (Martins et al., 2013).

$O$ reconhecimento dos passivos contingentes ambientais, segundo o CPC 25, apresenta dois tipos de obrigações: (1) a não formalizada; e (2) a legal. A obrigação não formalizada provém de ações da empresa quando o evento cria possibilidades de que ela arque com determinadas responsabilidades diante de terceiros. Ainda segundo o autor, é o caso de a empresa ser obrigada a reparar algum dano causado ao meio ambiente; a empresa, por outro lado, aceita repará-lo por considerar a hipótese de que, no futuro, isso venha a se tornar uma obrigação legal, seja por princípios éticos ou por adesão a práticas e políticas para tal procedimento. A obrigação legal, por outro lado, origina-se por legislação ou contratos quando, por exemplo, há penalidades ou geração de custos para a empresa, como no caso de recuperação de áreas ambientais atingidas por suas ações, ou descontaminações de rios (Leal, Costa, Oliveira, \& Rebouças, 2015).

O CPC 25 determina que, existindo um passivo cujo montante é mensurável com segurança, este deve ser provisionado. Se houver apenas a possibilidade de esse passivo existir, deve ser divulgado como passivo contingente. Já na situação em que a existência do passivo e a saída de recursos para possível liquidação seja muito pequena (remota), nada deverá ser divulgado.

No tocante às provisões e passivos contingentes ambientais, em casos cabíveis as entidades devem divulgar os itens exigidos no CPC 25, que, embora não trate diretamente da esfera ambiental, se aplica a todos os casos. Na hipótese de alguns itens não serem evidenciados porque a empresa não os pratica, a organização precisará divulgá-los, esclarecendo que esse determinado item não condiz com sua realidade. Murcia e Santos (2009) ressalta que, como se trata de uma divulgação voluntária, devido à não obrigatoriedade, as entidades possuem liberdade na elaboração do escopo, período e no modo de divulgar essas informações aos usuários.

De acordo com Dye (2001), essa divulgação é um caso especial da Teoria dos Jogos, cuja a principal premissa é a de que a entidade só divulgará voluntariamente informações favoráveis, dado o efeito positivo sobre os agentes de mercado. O raciocínio é que os benefícios da divulgação devem ser superiores aos custos incorridos nela, do contrário, as empresas não a realizarão (Angonese, Sanches, \& Bezerra, 2014; Cunha \& Ribeiro, 2008).

Entretanto, Cunha e Ribeiro (2008) argumentam que "a divulgação de informações pela contabilidade merece especial atenção na discussão corporativa, pois constitui uma das formas mais importantes de que os gestores dispõem para comunicar-se com os investidores e o mercado em geral". Tal discurso já perdura por várias décadas, como tratado no estudo de Kennedy, Mitchell e Sefcik (1998), os quais verificaram que os valores contínuos nas evidenciações de passivos contingentes ambientais impactam as análises dos stakholders no que se refere tanto à assimilação de risco de investimento, quanto às decisões do capital aplicado nesse investimento.

\subsection{Estudos anteriores}

Verificar a existência de relação entre divulgação ambiental voluntária e alguns fatores que podem explicar os determinantes desse tipo de evidenciação, bem como analisar o impacto dessas divulgações, especialmente no que tange à área ambiental, em alguns fatores financeiros e econômicos das entidades (como valor de mercado, rentabilidade e tamanho das organizações) tem sido o foco de algumas pesquisas. Tais estudos buscam associar alguns 
desses fatores às práticas do disclosure, principalmente os que têm mais impacto em relação aos stakholders.

O estudo realizado por Rufino e Machado (2015) buscou identificar os determinantes da divulgação voluntária no sentido social de 100 empresas listadas na BM\&F Bovespa, entre os anos de 2010 a 2012. Os resultados dessa pesquisa revelaram que o retorno sobre 0 patrimônio líquido, o tamanho, o setor regulado e a reputação da entidade foram as razões mais determinantes da evidenciação voluntária social. Verificou-se, ainda, que os usuários externos também podem influenciar o disclosure voluntário.

Por outro lado, Silva, Alexandre, Freitas \& Silva (2014), na mesma linha de pesquisa, analisaram as demonstrações contábeis, no ano de 2012, de 43 entidades consideradas de alto impacto ambiental, de acordo com a Lei $\mathrm{n}^{0}$ 10.165/00. A partir dos resultados encontrados, os autores perceberam que o fato de as organizações terem maior índice de vendas não influencia proporcionalmente o aumento da quantidade do disclosure ambiental, e aquelas entidades que são auditadas pelas quatro maiores empresas de auditoria do mundo, as Big Four, têm a tendência de divulgar mais em relação àquelas que não são auditadas. Diferente dos estudos apresentados nesta seção, esta pesquisa concluiu que a rentabilidade das empresas não influencia na quantidade da evidenciação.

Murcia e Santos (2009) e Angonese et al. (2014) estudaram, respectivamente, os determinantes do disclosure voluntário em 100 empresas não financeiras em 2007, e os fatores que explicam divulgações voluntárias na internet. Os autores divergiram em alguns pontos, mas chegaram à mesma conclusão no que tange à rentabilidade como não determinante da evidenciação. Eles concordaram que existe uma significância estatística referente às variáveis tamanho e governança corporativa, e divergiram no fator auditoria, pois Murcia e Santos (2009) concluíram que esse ponto se mostra insignificante na determinação do disclosure voluntário, enquanto Angonese et al. (2014) demostraram que o tamanho da firma de auditoria é um fator determinante para tal divulgação, concordando, nesse ponto, com o estudo de Silva et al. (2014).

Sobre o cumprimento das exigências de divulgação de provisões e passivos contingentes que constam no CPC 25, Suave, Codesso, Pinto, Vicente e Lunkes (2013) investigaram se as entidades com ações mais negociadas na BM\&F Bovespa atendiam tal pronunciamento. Os resultados da pesquisa mostraram que as organizações evidenciam especialmente processos judiciais associados a fatores fiscais, trabalhistas e também cíveis, enquanto as contingências ambientais possuem menor índice de divulgação. Quanto aos itens solicitados pelo CPC 25, constatou-se que as empresas atendem principalmente a descrição da natureza, estimativas de efeitos financeiros, imprecisões em relação a valores e períodos de ocorrência, e critérios de mensuração. Esses autores concluem que as entidades não evidenciam suas informações com a devida qualidade, pois não demonstram sua realidade.

Conforme Akerlof (1970), as organizações com maior rentabilidade são propícias a divulgar mais informações, a fim de se diferenciarem daquelas menos rentáveis e, assim, diminuírem o risco de seleção adversa. Corroborando o exposto, Gray, Meek e Roberts (1995) afirmam que as entidades mais rentáveis têm incentivos para se diferenciarem daquelas com menor rentabilidade, com o objetivo de levantar capital nas melhores condições disponíveis, por isso tendem a divulgar mais informações.

Lang e Lundholm (1993) afirmam que uma das formas de as empresas com maior rentabilidade se diferenciarem daquelas menos rentáveis é a evidenciação de informações de cunho ambiental, assumindo para os investidores do mercado financeiro suas ações no que se refere ao meio ambiente e mostrando, desse modo, uma vantagem diante dos concorrentes.

Em seu estudo, Lu e Abeysekera (2014) averiguaram a influência dos investidores e as características das práticas de evidenciação social e ambiental das empresas chinesas consideradas socialmente responsáveis, identificadas por uma lista de classificação. Após analisarem os relatórios, os autores verificaram que as variáveis rentabilidade, tamanho da empresa e classificação da indústria possuem associações estatisticamente significantes com a divulgação social e ambiental.

Fonteles, Nascimento, Ponte e Rebouças (2012) analisaram os determinantes da evidenciação de provisões e contingências pelas companhias listadas na BM\&F Bovespa, e os resultados da pesquisa indicaram um grau muito baixo em relação ao cumprimento da norma: 
cerca de $32 \%$ dos itens exigidos pelo CPC 25. No que se refere aos determinantes, constatouse que o índice de divulgação das contingências é motivado principalmente pelos ramos de energia elétrica, eletroeletrônicos, telecomunicações, minerais não metálicos, comércio e também pelo tamanho e rentabilidade das organizações, visto que essas variáveis foram significantes estatisticamente. O mesmo não aconteceu com as variáveis liquidez e setor de construção, que se mostraram insignificantes para a evidenciação.

Este estudo, por sua vez, segue a vertente de que a divulgação discricionária das provisões e passivos contingentes ambientais está diretamente associada à rentabilidade das empresas com alto potencial poluidor.

\subsection{Formulação de hipótese}

Pelas evidências empíricas encontradas, a generalidade dos estudos sugere a existência de uma relação positiva entre a performance ambiental e financeira das empresas (Stanwick \& Stanwick, 1998, Gottsman \& Kessler, 1998, Austin, Alberini, \& Videras, 1999, Cohen, Fenn, \& Konar, 1997).

Já no tocante à divulgação das informações ambientais, o estudo de latridis (2013) verificou que a evidenciação de informações ambientais está ligada ao bom desempenho das entidades, especialmente em setores de produtos químicos, papel e indústria, metais e mineração, que fazem parte do grupo de alto potencial poluidor.

Partindo desse pressuposto, esta pesquisa irá se basear na Teoria da Divulgação Discricionária (Verrecchia, 2001) para associar a divulgação de informações sobre riscos ambientais e a rentabilidade das empresas. A expectativa é que haja uma relação positiva entre a divulgação de provisões e passivos contingentes ambientais e a rentabilidade das entidades de alto potencial poluidor listadas na B3. Dessa forma, foi testada a seguinte hipótese:

$\mathbf{H}_{1}$ : A rentabilidade das empresas de alto potencial poluidor está positivamente relacionada com o disclosure de provisões e passivos contingentes ambientais das empresas de alto potencial poluidor listadas na B3.

\section{METODOLOGIA}

Esta pesquisa se caracteriza, quanto aos objetivos, como descritiva, pois buscou descrever a relação entre a rentabilidade e o disclosure de provisões e passivos contingentes ambientais das empresas de alto potencial poluidor listadas na B3, no período de 2011 a 2016. Quanto à abordagem do problema, é considerada quantitativa, uma vez que empregou instrumentos de análise estatística (Beuren \& Raupp, 2006).

A definição das variáveis, apresentadas na Tabela 1, teve por base os trabalhos de Uyar e Kiliç (2012) e Leal et al. (2015). A coleta de informações econômico-financeiras das empresas da amostra foi feita na base de dados da Economática $\AA^{\circledR}$, na qual é possível verificar informações relativas ao desempenho econômico-financeiro das empresas em seus demonstrativos consolidados. Já para construir as variáveis Divulgação de provisões e passivos contingentes ambientais (DIVULG), Índice de Sustentabilidade Empresarial (ISE) e Governança Corporativa (GOV), os dados foram extraídos do site da B3, por meio de análise documental de notas explicativas e relatórios de sustentabilidade. 
Tabela 1

Variáveis da pesquisa

\begin{tabular}{|c|c|c|c|c|c|}
\hline Var. & Tipo & Descrição & Cálculo & $\begin{array}{c}\text { Efeito } \\
\text { esperado }\end{array}$ & Referências \\
\hline DIVULG & D & $\begin{array}{l}\text { Divulgação de } \\
\text { informações sobre } \\
\text { provisões e } \\
\text { passivos } \\
\text { contingentes } \\
\text { ambientais } \\
\text { conforme CPC } 25 \text {. }\end{array}$ & $\begin{array}{l}\text { (0) para as empresas } \\
\text { que não divulgaram, } \\
\text { (1) para as que } \\
\text { divulgaram; } \\
\text { posteriormente, } \\
\text { obtém-se o total de } \\
\text { elementos e verifica- } \\
\text { se a proporção do } \\
\text { item divulgado em } \\
\text { relação ao total de } \\
\text { métricas } \\
\end{array}$ & & \\
\hline RENT & 1 & $\begin{array}{l}\text { Rentabilidade } \\
\text { sobre o } \\
\text { investimento (ROA) }\end{array}$ & $\begin{array}{l}\text { Lucro Líquido/ Ativo } \\
\text { Total }\end{array}$ & + & $\begin{array}{l}\text { Fonteles et al. (2012); } \\
\text { Rufino e Machado } \\
\text { (2015) }\end{array}$ \\
\hline VM & C & Valor de Mercado & $\begin{array}{l}\text { Log do valor de } \\
\text { mercado das ações }\end{array}$ & + & $\begin{array}{l}\text { Sousa, Silva, Ribeiro e } \\
\text { Weffort (2014) }\end{array}$ \\
\hline ENDIV & C & Endividamento & Exigível Total/PL & + & $\begin{array}{l}\text { Stulz (1990); Durand } \\
(1959)\end{array}$ \\
\hline ISE & C & $\begin{array}{l}\text { Participação no } \\
\text { ISE (dummy) }\end{array}$ & $\begin{array}{l}\text { (0) para as empresas } \\
\text { que não pertencem ao } \\
\text { ISE, (1) para as que } \\
\text { pertencem }\end{array}$ & + & Rufino e Monte (2014) \\
\hline GOV & $\mathrm{C}$ & $\begin{array}{l}\text { Aderência a um } \\
\text { dos níveis de } \\
\text { Governança } \\
\text { Corporativa } \\
\text { (dummy) }\end{array}$ & $\begin{array}{l}\text { (0) para as empresas } \\
\text { que não aderiram a } \\
\text { um dos níveis de GC, } \\
\text { (1) para as que } \\
\text { aderiram }\end{array}$ & + & $\begin{array}{l}\text { Leal e Silva (2005); } \\
\text { Murcia e Santos } \\
(2009)\end{array}$ \\
\hline TAM & $\mathrm{C}$ & $\begin{array}{l}\text { Tamanho da } \\
\text { empresa }\end{array}$ & $\begin{array}{l}\text { Logaritmo natural do } \\
\text { Ativo Total }\end{array}$ & + & $\begin{array}{l}\text { Murcia e Santos } \\
\text { (2009); Rufino e Monte } \\
(2014)\end{array}$ \\
\hline
\end{tabular}

Nota: Var. - Variáveis; D - Dependente; I- Independente; C - Controle; CPC - Comitê de Pronunciamentos Contábeis; PL - Patrimônio Líquido; ISE - Índice de Sustentabilidade Empresarial; GOV - Governança Corporativa.

Fonte: Adaptado de Leal, P. H., Costa, B. M. N., Oliveira, M. C., \& Rebouças, S. M. D. P. (2015). Divulgação de Provisões e Passivos Contingentes Ambientais Sob a Ótica da Teoria Institucional. Anais do Congresso da Associação Nacional dos Programas de Pós-Graduação em Ciências Contábeis, Curitiba, PR, Brasil, 9.

A mensuração da variável DIVULG ocorreu em função do atendimento dos quesitos listados na Tabela 2. O procedimento utilizado foi atribuir valor 0 àqueles itens que não foram identificados nas notas explicativas, e valor 1 para os que foram divulgados pelas empresas. Posteriormente calculou-se a proporção do item divulgado em relação ao total de métricas.

Segundo o CPC 25 (2009), cada informação deve ser divulgada pela empresa, exceto se algum item não for obrigatório para ela; se esse for o caso, a empresa deverá justificar o porquê de não se aplicar. Assim, cada item justificado será considerado como uma informação divulgada na análise das notas explicativas (Leal et al., 2015). 
Tabela 2

Itens de divulgação de provisões e passivos contingentes conforme o CPC 25

\section{Provisões ambientais}

Valor contábil no início e no fim do período

Provisões adicionais feitas no exercício, incluindo aumento nas provisões existentes

Valores utilizados (ou seja, incorridos e baixados contra a provisão) durante o exercício

Valores não utilizados e revertidos durante o exercício

Breve descrição da natureza da obrigação

Cronograma esperado para as saídas de benefícios econômicos

Indicação das incertezas sobre o valor ou o cronograma das saídas de benefícios econômicos

valor de qualquer reembolso esperado, declarando o valor de qualquer ativo que tenha sido reconhecido por conta desse reembolso esperado

\begin{tabular}{l} 
Passivos contingentes ambientais \\
\hline Breve descrição da natureza do passivo contingente \\
\hline Estimativa de seu efeito financeiro quando praticável \\
\hline Aumento durante o período no valor descontado a valor presente proveniente da passagem do tempo e o efeito de \\
qualquer mudança na taxa de desconto \\
\hline Incertezas relacionadas ao valor ou momento de ocorrência de qualquer saída quando praticável \\
\hline Possibilidade de qualquer reembolso quando praticável \\
\hline Fonte: Leal, P. H., Costa, B. M. N., Oliveira, M. C., \& Rebouças, S. M. D. P. (2015). Divulgação de Provisões e Passivos \\
Contingentes Ambientais Sob a Ótica da Teoria Institucional. Anais do Congresso da Associação Nacional dos Programas de Pós- \\
Graduação em Ciências Contábeis, Curitiba, PR, Brasil, 9.
\end{tabular}

A população deste estudo é formada por todas as empresas de alto potencial poluidor listadas na B3, cujas ações foram negociadas no período de 2011 a 2016. Todavia, das 39 empresas registradas nessa categoria, uma foi excluída, por não dispor de todas as informações necessárias à mensuração das variáveis aplicadas na pesquisa. Assim, a amostra final compreendeu 38 empresas, conforme apresentado na Tabela 3.

Para determinar se as empresas pertencem ao setor de alto potencial poluidor, utilizouse o Anexo VIII da Lei no 10.165/2000, que dispõe sobre a Política Nacional do Meio Ambiente. Esse anexo classifica as atividades econômicas das empresas em pequeno, médio e alto impacto ambiental.

Tabela 3

Empresas que compuseram a amostra da pesquisa

\begin{tabular}{|c|c|c|c|}
\hline $\begin{array}{l}\text { Potencial } \\
\text { Poluidor }\end{array}$ & $\begin{array}{c}\text { Setores da Lei } \mathrm{n}^{\circ} \\
10.165 / 2000\end{array}$ & Setores da B3 & Empresas \\
\hline \multirow{14}{*}{ Alto } & \multirow{4}{*}{$\begin{array}{l}\text { Extração e tratamento } \\
\text { de minerais }\end{array}$} & \multirow{4}{*}{ Minerais Metálicos } & Bradespar \\
\hline & & & Litel \\
\hline & & & MMX Mineração e Metalicos S.A. \\
\hline & & & Vale S.A. \\
\hline & \multirow{10}{*}{ Indústria Metalúrgica } & \multirow{4}{*}{ Artefato de Ferro e Aço } & Fibam \\
\hline & & & Mangels Indl \\
\hline & & & Panatlantica \\
\hline & & & Tekno \\
\hline & & Artefato de Cobre & Paranapanema \\
\hline & & \multirow{5}{*}{ Siderúrgica } & Ferbasa \\
\hline & & & Gerdau \\
\hline & & & Gerdau Met \\
\hline & & & Sid Nacional \\
\hline & & & Usiminas \\
\hline
\end{tabular}


Tabela 3 (continuação)

\begin{tabular}{|c|c|c|c|}
\hline $\begin{array}{l}\text { Potencial } \\
\text { Poluidor }\end{array}$ & $\begin{array}{l}\text { Setores da Lei } \mathrm{n}^{\circ} \\
10.165 / 2000\end{array}$ & Setores da B3 & Empresas \\
\hline \multirow{24}{*}{ Alto } & \multirow{6}{*}{ Papel e Celulose } & \multirow{6}{*}{ Papel e Celulose } & Celul Irani \\
\hline & & & Firbia \\
\hline & & & Klabin S/A \\
\hline & & & Santher \\
\hline & & & Suzano Hold \\
\hline & & & Suzano Papel \\
\hline & \multirow{7}{*}{ Indústria Química } & \multirow{3}{*}{ Petroquímico } & Brasken \\
\hline & & & Elekeiroz \\
\hline & & & GPC Part \\
\hline & & \multirow{2}{*}{ Fertilizantes e Defensivos } & Fer Heringer \\
\hline & & & Nutriplant \\
\hline & & \multirow{2}{*}{ Químico Diversos } & Cristal \\
\hline & & & Unipar \\
\hline & \multirow{11}{*}{$\begin{array}{l}\text { Transporte, terminais, } \\
\text { depósitos e comércio }\end{array}$} & \multirow{9}{*}{$\begin{array}{l}\text { Exploração, Refinação e } \\
\text { Distribuição }\end{array}$} & CosanLtd \\
\hline & & & Cosan \\
\hline & & & Nova Oleo \\
\hline & & & OGX Petroleo \\
\hline & & & \begin{tabular}{|l|} 
Pet Manguinh \\
\end{tabular} \\
\hline & & & Petrobras \\
\hline & & & Petrorio \\
\hline & & & QGEP Part \\
\hline & & & Ultrapar \\
\hline & & \multirow{2}{*}{ Equipamentos e Serviços } & Lupatech S.A \\
\hline & & & OSX Brasil \\
\hline
\end{tabular}

Fonte: Santos, L. M. S. (2016). Fatores explicativos da evidenciação de informações ambientais das empresas potencialmente poluidoras listadas na BM\&FBovespa. Dissertação de Mestrado em Ciências Contábeis, Universidade Federal da Paraíba, João Pessoa, PB, Brasil.

O período analisado neste estudo foi de 2011 a 2016, pois em 2010 o CPC 25 foi emitido, entretanto, os reflexos de sua adoção puderam ser identificados no exercício seguinte. O objetivo desse Pronunciamento Técnico é estabelecer critérios de reconhecimento e bases de mensuração apropriados a provisões, passivos e ativos contingentes. Visa também a divulgação de informações suficientes nas notas explicativas para permitir que os usuários entendam a sua natureza, oportunidade e valor.

Para testar a hipótese de pesquisa, foi utilizado o modelo de regressão linear múltipla com dados em painel, correspondente ao período de 2011 a 2016. Segue o modelo econométrico utilizado na estimação:

$$
\text { DIVULG }_{i t}=\alpha+\beta_{1} R E N T_{i t}+\beta_{2} V M_{i t}+\beta_{3} E N D I V_{i t}+\beta_{4} I S E_{i t}+\beta_{5} G_{\text {OV }}+\beta_{6} T_{A M}+\varepsilon(1)
$$

Onde a variável dependente é a Divulgação de provisões e passivos contingentes ambientais (DIVULG), tendo como variável independente a Rentabilidade (RENT), e como variáveis de controle Tamanho (TAM), Endividamento (ENDIV), Valor de Mercado (VM), Governança Corporativa (GOV) e a participação das empresas no ISE (Índice de Sustentabilidade Empresaria).

\section{APRESENTAÇÃO E ANÁLISE DOS RESULTADOS}

Esta seção discutirá os resultados da pesquisa. Primeiramente, apresenta-se uma análise descritiva das variáveis, com o intuito de observar seus comportamentos e a 
associação entre elas; posteriormente utiliza-se o modelo de regressão com dados em painel desbalanceado, a fim de examinar a hipótese da pesquisa e, assim, analisar se a rentabilidade das empresas de alto potencial poluidor está positivamente relacionada com o disclosure de provisões e passivos contingentes ambientais.

\subsection{Análise descritiva dos dados}

$\mathrm{Na}$ Tabela 4 observa-se que algumas variáveis, tais como RENT (35.5297), ENDIV (10.9375) e TAM (3.5149), apresentaram maior dispersão dos dados em torno da média, ao contrário das variáveis DIVULG (0.1460), GOV (0.4754) e ISE (0.4907), cujos resultados mostraram menor dispersão dos dados, pelo fato de serem variáveis dummies. A variável TAM (21.0801) e VM (13.8523) são as de maiores médias. Percebe-se, ainda, que a diferença entre a média e a mediana das variáveis RENT, VM, ENDIV e TAM demonstra que a distribuição dos dados é assimétrica.

Tabela 4

Estatística descritiva dos dados

\begin{tabular}{ccccccc}
\hline Variável & Observações & Média & $\begin{array}{l}\text { Desvio } \\
\text { Padrão }\end{array}$ & Mediana & Mínimo & Máximo \\
\hline DIVULG & 228 & 0.1348 & 0.1460 & 0.1538 & 0 & 0.5384 \\
\hline RENT & 225 & 2.3857 & 35.5297 & 0.0387 & -6.6172 & 532.428 \\
\hline VM & 218 & 13.8523 & 2.7052 & 13.5150 & 7.4204 & 19.4907 \\
\hline ENDIV & 226 & 3.3120 & 10.9375 & 1.8435 & -32.6294 & 64.0001 \\
\hline ISE & 228 & 0.6008 & 0.4907 & 1 & 0 & 1 \\
\hline GOV & 228 & 0.6578 & 0.4754 & 1 & 0 & 1 \\
\hline TAM & 225 & 21.0801 & 3.5149 & 21.2413 & 9.333 & 27.5258 \\
\hline
\end{tabular}

Nota. RENT: Retorno sobre os ativos; DIVULG: Divulgação de informações sobre provisões e passivos contingentes ambientais conforme CPC 25; VM: Valor de Mercado; ENDIV: Endividamento; ISE: Participação no ISE; GOV: Aderência a um dos níveis de Governança Corporativa; TAM: Tamanho da Empresa.

Fonte: Dados da pesquisa (2017)

Considerando os valores apresentados na Tabela 5, observa-se que a variável DIVULG se correlaciona positivamente com quase todas as variáveis do estudo, exceto com a Rentabilidade do Investimento, que apresenta uma correlação negativa (-0.0611), porém com baixa intensidade. $O$ valor de mercado (VM) foi a variável explicativa que mostrou maior correlação com a DIVULG, com 44,21\%.

Tabela 5

Correlação entre as variáveis

\begin{tabular}{cccccccc}
\hline & DIVULG & RENT & VM & ENDIV & ISE & GOV & TAM \\
\hline DIVULG & 1.0000 & & & & & & \\
RENT & -0.0611 & 1.0000 & & & & & \\
VM & 0.4421 & -0.0307 & 1.0000 & & & & \\
ENDIV & 0.0603 & -0.0047 & 0.1972 & 1.0000 & & & \\
ISE & 0.3995 & 0.0566 & 0.5922 & 0.0878 & 1.0000 & & \\
GOV & 0.2297 & 0.0435 & 0.5185 & -0.0392 & 0.5639 & 1.0000 & \\
TAM & 0.3153 & -0.0466 & 0.5290 & 0.0889 & 0.3247 & 0.2971 & 1.0000 \\
\hline
\end{tabular}

Fonte: Dados da Pesquisa (2017).

Quanto à interação das demais variáveis, verifica-se que a variável VM se relaciona forte e positivamente com as variáveis ISE (0.5922), GOV (0.5185) e TAM (0,5290), assim como ISE se relaciona com GOV (0.5639), sendo as demais variáveis relacionadas umas com as outras de maneira menos intensa. 


\subsection{Análise dos resultados econométricos}

Após uma breve análise descritiva, a próxima etapa foi a estimação do modelo econométrico. Para tanto, com a intensão de estabelecer o painel mais indicado para análise dos dados desta pesquisa, foram realizados os testes de Chow e Hausman.

A partir do teste Chow (Prob $>\mathrm{F}=0.0000$ ) e do teste de Hausman (Prob $>$ Chi2 $=0.0447$ ), observou-se, respectivamente, que há evidências para se rejeitar a hipótese de que os efeitos do painel não são significantes - ou seja, existe significância em relação ao efeito das empresas e dos anos; e que o modelo de efeitos fixos é preferível em relação ao aleatório. Pode-se dizer, com isso, que o painel de efeitos fixos é mais adequado do que a regressão linear múltipla para a amostra em questão.

Aplicaram-se também os testes de Wooldridge (Prob $>\mathrm{F}=0.0185$ ) e de Wald (Prob $>$ chi2 $=0,000$ ) para verificar, respectivamente, a autocorrelação e heterocedasticidade. Os resultados constataram problemas de autocorrelação e heteroscedasticidade. A correção desses dois problemas realizou-se a partir do teste de Driscoll e Kraay (1998), que é fundamentado nos erros padrões dos coeficientes estimados por efeitos fixos, sendo esses erros robustos à heterocedasticidade, correlação temporal e espacial (Missio, 2012).

Analisando o resultado da regressão de efeitos fixos, destacado na Tabela 6, é possível afirmar que, com exceção do tamanho (TAM), todas as demais variáveis (RENT, VM, ENDIV e ISE) possuem significância estatística (10\%, 5\%, 1\% e 5\%, respectivamente). Nota-se, ainda, que GOV foi omitida do modelo, por ser uma variável dummy fixa ao longo do painel, desse modo, não se podem estimar seus coeficientes na regressão com dados em painel.

Considerando a variável independente (RENT), verificou-se que possui um coeficiente negativo $(-8,51 e-5)$ e com significância estatística ( $p$-valor $=0,077)$; dessa maneira, é possível inferir que existe uma relação indireta entre Rentabilidade (RENT) e a variável dependente (DIVULG), sugerindo, com isso, que as empresas mais rentáveis divulgam menos informações sobre provisões e passivos contingentes ambientais.

Logo, a hipótese de que a rentabilidade das empresas de alto potencial poluidor está positivamente relacionada com o disclosure de provisões e passivos contingentes ambientais foi rejeitada. O resultado da pesquisa é consistente com os trabalhos de Silva et al. (2014), Murcia e Santos (2009) e Angonese et al. (2014), os quais revelaram que a rentabilidade não influenciava na divulgação de informações ambientais. Em contrapartida, as pesquisas de Rufino e Machado (2015) e Fonteles et al. (2012) identificaram uma relação positiva entre rentabilidade e evidenciação ambiental.

Tabela 6

Resultados da regressão com dados em painel de efeitos fixos robusta

\begin{tabular}{|c|c|c|c|c|}
\hline VAR. EXPLICATIVAS & COEFICIENTE & ERRO & $\mathrm{T}$ & P-VALOR \\
\hline RENT & $-8.51 e-5^{*}$ & $4.68 e-5$ & -1.82 & 0.077 \\
\hline VM & $-0.0087^{\star *}$ & 0.0036 & -2.41 & 0.021 \\
\hline ENDIV & $0.0004^{* \star *}$ & $8.89 e-5$ & 4.94 & 0.000 \\
\hline ISE & $-0.0091^{\star *}$ & 0.0025 & -3.63 & 0.001 \\
\hline GOV & & (Omitida) & & \\
\hline TAM & 0.0020 & 0.0015 & 1.29 & 0.207 \\
\hline Constante & 0.2232 & 0.0332 & 6.72 & 0.000 \\
\hline Observações: & 215 & & & \\
\hline Within R-squared & 0.0119 & & & \\
\hline Teste F: & 0.0000 & & & \\
\hline \multicolumn{5}{|c|}{ Equação: DIVULG it $=\alpha+\beta 1$ RENT $+\beta 2$ VM it $+\beta 3$ ENDIV it $+\beta 4$ ISE it $+\beta 5$ GOV it $+\beta 6$ TAM it $+\varepsilon$} \\
\hline \multicolumn{5}{|c|}{$\begin{array}{l}\text { Nota. }{ }^{*} \mathrm{p}<0,10 ;{ }^{* *} \mathrm{p}<0,05 ;{ }^{* * *} \mathrm{p}<0,01 \text {; DIVULG: divulgação de informações sobre provisões e passivos contingentes ambientais } \\
\text { conforme CPC } 25 ; \text { RENT: retorno sobre os ativos; VM: valor de mercado; ENDIV: endividamento; ISE: participação no ISE; GOV: } \\
\text { aderência a um dos níveis de governança corporativa; TAM: tamanho da empresa. } \\
\text { Fonte: Dados da pesquisa (2017). }\end{array}$} \\
\hline
\end{tabular}

As variáveis VM ( $p$-valor $=0,021)$ e ISE $(p$-valor $=0,001)$ seguiram em direção oposta à variável RENT, visto que obtiveram significância estatística e apresentaram coeficientes negativos de $-0,0087$ e -0,0091, respectivamente, indicando, assim, que quanto maior o valor 
de mercado das empresas, e se elas estiverem listadas no ISE, menor será o volume de disclosure de provisões e passivos contingentes.

Com relação ao valor de mercado, esse resultado corrobora as evidências verificadas por Sousa et al. (2014), as quais mostraram um possível conflito de interesses, tendo em vista que a divulgação de informações implica em custos para as empresas, gerando como consequência uma redução de ganhos para os investidores. Essa constatação diverge de Santos, Araújo e Leite (2016), que identificaram que as empresas que evidenciam informações sobre provisões e passivos contingentes ambientais possuem maior valor de mercado do que aquelas que não divulgam tais informações.

No que diz respeito à variável ISE, o resultado divergiu da pesquisa de Rufino e Monte (2014), a qual mostrou uma relação positiva entre sustentabilidade e divulgação discricionária, sugerindo que a variável ISE influencia diretamente a evidenciação de informações. Esse resultado também contrariou o estudo de Garcia e Orsato (2013), os quais não encontraram diferenças estatísticas significativas entre o fato de uma empresa aderir ao ISE e o impacto no valor das ações da empresa.

Quanto ao endividamento (ENDIV), foi observada uma relação positiva $(0,0004)$ e significante ( $p$-valor $=0,0000$ ) com a variável DIVULG, evidenciando que empresas mais endividadas possuem um nível mais elevado de disclosure de provisões e passivos contingentes ambientais. Esse resultado divergiu do estudo apresentado por Rufino e Monte (2014), o qual chegou à conclusão de que quanto maior o endividamento menor é a divulgação discricionária de informações nas entidades. Também contrariou o achado de Murcia e Santos (2009), que identificaram que a variável ENDIV se mostrou insignificante na determinação de divulgação discricionária.

Por fim, ao analisar a variável TAM, observou-se que não houve significância estatística, ou seja, o tamanho das empresas não possui relação com o disclosure de provisões e passivos contingentes, resultado semelhante ao encontrado na pesquisa de Santos, Lucena e Duarte (2015), porém contrário aos achados de Murcia e Santos (2009), Rufino e Monte (2014), que mostraram que o tamanho das entidades é um fator determinante da divulgação discricionária.

\section{CONCLUSÕES}

Este trabalho teve o propósito de analisar se a rentabilidade das empresas de alto impacto poluidor listadas na B3 está relacionada positivamente com o disclosure de provisões e passivos contingentes ambientais, entre os anos de 2011 a 2016. A amostra da pesquisa compreendeu 38 empresas pertencentes ao grupo de alto potencial poluidor, determinadas de

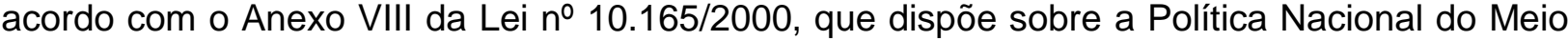
Ambiente.

Os dados analisados nesta pesquisa foram coletados na base Economática $\AA_{\text {, }}$ e organizados em um painel desbalanceado, visto que não foi possível obter todos os dados para todas as empresas classificadas com alto grau de alto potencial. A partir do modelo de regressão com dados em painel com robustez, averiguou-se que, com exceção do tamanho (TAM), todas as demais variáveis (RENT, VM, ENDIV e ISE) possuem significância estatística, (10\%, 5\%, $1 \%$ e $5 \%$, respectivamente); ou seja, podem explicar o disclosure de provisões e passivos contingentes ambientais. A variável GOV foi omitida do modelo, por ser uma variável dummy fixa ao longo do painel.

No que diz respeito à hipótese $\left(\mathbf{H}_{1}\right.$ : $\mathrm{A}$ rentabilidade das empresas de alto potencial poluidor está positivamente relacionada com o disclosure de provisões e passivos contingentes ambientais), houve rejeição, pois, apesar de haver significância, obteve-se um coeficiente negativo, mostrando que as empresas mais rentáveis não são necessariamente as que mais divulgam informações sobre provisões e passivos contingentes ambientais.

Uma possível explicação para o resultado encontrado refere-se ao fato de que a implantação de uma obrigatoriedade legal para o disclosure de provisões e passivos contingentes ambientais implica num maior custo, que, por sua vez, reflete-se no desempenho da empresa, dada a possibilidade de conflito de interesses e expectativas de uma redução de 
ganhos por parte dos acionistas/investidores. Por outro lado, esse resultado pode ser explicado pelo fato de as empresas mais rentáveis já se diferenciarem de suas concorrentes no mercado de capitais, com indicadores financeiros positivos e, por esta razão, elas acabam não divulgando "todas" as informações, se perceberem que isso atrapalhará seus resultados.

Assim, o resultado desta pesquisa aponta para a necessidade de uma maior discussão sobre a regulação da evidenciação de provisões e passivos contingentes ambientais, visto que as empresas tendem a divulgar mais dados quando pressionadas por instrumento regulador. Além disso, é extremamente importante uma padronização na divulgação de informações dessa natureza, principalmente pelas empresas de alto potencial poluidor, no processo decisório de investidores e outras partes interessadas.

Ressalta-se, ainda, que este resultado pode ter sofrido influências de algumas limitações no decorrer do estudo, como a subjetividade da análise de conteúdo para determinar a variável DIVULG, e o fato de a análise não ter levado em consideração o setor em que cada empresa atua.

Propõe-se para pesquisas futuras a observações dessas limitações, bem como a utilização de outras variáveis e métricas para expandir os estudos e o uso de outros níveis de classificação, como empresas de pequeno e médio impacto ambiental, conforme disposto no Anexo VIII da Lei no 10.165/2000.

A contribuição desta pesquisa para a literatura está em revelar se existe relação positiva entre a rentabilidade das empresas de alto impacto poluidor, listadas na B3, e o disclosure de provisões e passivos contingentes ambientais. Embora algumas pesquisas, como a de Rufino e Machado (2015) e Fonteles et al. (2012), que trataram dos determinantes de divulgação discricionária, considerem que as empresas mais rentáveis tendem a divulgar mais informações, os resultados encontrados aqui mostraram que isso não se aplica quando o disclosure abrange provisões e passivos contingentes ambientais.

\section{REFERÊNCIAS}

Akerlof, G. (1970). The market for lemons: quality, uncertainty and market mechanism. Quarterly Journal of Economic, 84(3), 488-500.

Angonese, R., Sanches, J. R., \& Bezerra, F. A. (2014). Determinantes da divulgação de informações voluntárias por meio da internet. ConTexto, 14(26), 19-31.

Austin, D., Alberini, A., \& Videras, J. (1999). Is There a Link Between a Firm's Environmental and Financial Performance?. Paper presented at NBER Summer Institute Public Economics Workshop: Public Policy and the Environment, Cambridge.

Baldoino, E. \& Borba, J. A. (2015). Passivos contingentes na bolsa de valores de Nova York: uma análise comparativa entre as empresas estrangeiras. Revista de Contabilidade e Organizações, 9(23), 58-81.

Beuren, I.M. \& Raupp, F. M.(2006). Metodologia da pesquisa aplicável às ciências sociais. In I. M. Beuren \& F. M. Raupp (Orgs.) Como elaborar trabalhos monográficos em contabilidade: teoria e prática. São Paulo: Atlas.

Bewley, K. A. (1998). The economic consequences of financial reporting standards: the market valuation of environmental liabilities. Tese de Doutorado em Contabilidade, University of Waterloo, National Library of Canadá, Waterloo, Ontário, Canadá.

Bomfim, E. T., Teixeira, W. S, \& Monte, P. A. (2015). Relação entre o Disclosure da Sustentabilidade com a Governança Corporativa: Um Estudo nas Empresas Listadas no Ibrx-100. Revista Sociedade, Contabilidade e Gestão, 1(1), 6-28. 
Lei n. 10.165, de 27 de dezembro de 2000. Altera a Lei oㅡ 6.938, de 31 de agosto de 1981, que dispõe sobre a Política Nacional do Meio Ambiente, seus fins e mecanismos de formulação e aplicação, e dá outras providências. Recuperado de http://www.planalto.gov.br/ccivil_03/leis/L10165.htm.

Bushman, R. M. \& Smith, A. J. (2001). Financial accounting information and corporate governance. Journal of Accounting and Economics, 32(1), 237-333.

Caetano, T. P., Silva, T. B., Biesdorf, S., \& Leal, E. A. (2010). Evidenciação do Passivo Contingencial nas Demonstrações Contábeis: Um estudo nas Empresas de Papel e Celulose. Anais do Congresso USP de Controladoria e Contabilidade, São Paulo, SP, Brasil, 10.

Cohen, M. A., Fenn, S. A., \& Konar, S. (1997). Environmental and Financial Performance: are they related?. Discussion Paper, Vanderbilt University.

Comitê de Pronunciamentos Contábeis (CPC) (2009). CPC 25: Provisões, passivos contingentes ativos contingentes. Recuperado de http://www.cpc.org.br/CPC/DocumentosEmitidos/Pronunciamentos/Pronunciamento?ld=5 6

Cunha, J. V. A, \& Ribeiro, M. S. (2008). Divulgação voluntária de informações de natureza social: um estudo nas empresas brasileiras. Revista de Administração - Eletrônica, 1(6), $1-23$.

Dantas, J. A., Zendersky, H. C., Santos, S. C., \& Niyama, J. K. (2005). A dualidade entre os benefícios do disclosure e a relutância das organizações em aumentar o grau de evidenciação. Economia \& Gestão, 5(11), 56-76.

Driscoll, J. C., \& Kraay, A. C. (1998). Consistent Covariance Matrix Estimation with Spatially Dependent Panel Data. Review of Economics and Statistics, 80(4), 549-560.

Durand, D. (1959). The cost of capital, corporation finance, and the theory of investment: comment. The American Economic Review, 49(4), 639-655.

Dye, R. A. (2001). An evaluation of essays on disclosure and the disclosure literature in accounting. Journal of Accounting and Economics, 32(1-3), 181-235.

Fernandes, S. M. (2013). Fatores que Influenciam o Disclosure Ambiental: Um Estudo nas Empresas Brasileiras no Período de 2006 a 2010. Revista Ambiente Contábil, 5(2), 250267.

Fonteles, I. V., Nascimento, C. P. S., Ponte, V. M. R., \& Rebouças, S. M. D. P. (2012). Determinantes da Evidenciação de Provisões e Contingências por Companhias listadas na BM\&FBOVESPA. Revista Gestão Organizacional, 6(4), 85-98.

Garcia, A. S., \& Orsato, R. J. (2013). Índices de sustentabilidade empresarial: Porque participar? Anais do Encontro da ANPAD, Rio de Janeiro, RJ, Brasil, 37.

Gray, S. J., Meek, G. K., \& R. C. B. (1995). International Capital Market Pressures and Voluntary Annual Report Disclosures by U.S. and U.K. Multinationals. Journal of International Financial Management and Accounting, 6(1), 43-68.

Gottsman, L. \& Kessler, J. (1998). Smart Screened Investments: environmentally-screened equity funds that perform like conventional funds. Journal of Investing, 7(3), 15-24. 
latridis, G. E. (2013). Environmental disclosure quality: Evidence on environmental performance, corporate governance and value relevance. Emerging Markets Review, 14, $55-75$.

Kennedy, J., Mitchell, T., \& Sefcik, S. E. (1998). Disclosure of contingent environmental liabilities: some unintended consequences? Journal of Accounting Research, 36(2), 257277.

Kolk, A., Levy, D., \& Pinkse, J. (2008). Corporate responses in an emerging climate regime: The institutionalization and commensuration of carbon disclosure. European Accounting Review, 17(4), 719-745.

Lang, M. \& Lundholm, R. (1993). Cross-sectional Determinants of Analyst Ratings of Corporate Disclosures. Journal of Accounting Research, 31(2), 246-247.

Leal, P. H., Costa, B. M. N., Oliveira, M. C., \& Rebouças, S. M. D. P. (2015). Divulgação de Provisões e Passivos Contingentes Ambientais Sob a Ótica da Teoria Institucional. Anais do Congresso da Associação Nacional dos Programas de Pós-Graduação em Ciências Contábeis, Curitiba, PR, Brasil, 9.

Leal, R. P. C. \& Silva, A. L. C. (2005). Corporate Governance, Value and Dividend Payout in Brazil and Chile. Recuperado de http://www.istfin.eco.usi.ch/r_leal.pdf.

Lu, Y. \& Abeysekera, I. (2014). Stakeholders' Power, Corporate Characteristics, and Social and Environmental Disclosure: Evidence from China. Journal of Cleaner Production, 64, 426436.

Martins, E., Gelbcke, E. R., Santos, A., \& ludícibus, S. (2013). Manual de contabilidade societária: aplicada a todas as sociedades - De acordo com as normas internacionais $e$ do CPC. São Paulo: Atlas.

Missio, Fabricio. J. (2012). Câmbio Real e Crescimento: Novas Evidências Empíricas. Anais do Encontro Internacional da Associação Keynesiana Brasileira Keynesiana, São Paulo, SP, Brasil, 5.

Murcia, F. D. \& Santos, A. (2009). Fatores determinantes do nível de disclosure voluntário das companhias abertas no Brasil. Revista de Educação e Pesquisa em Contabilidade, 3(2), 72-95.

Nossa, V. (2002). Disclosure ambiental: uma análise do conteúdo dos relatórios ambientais de empresas do setor de papel e celulose em nível internacional. Tese de Doutorado em Ciências Contábeis, Universidade de São Paulo, SP, Brasil.

Oliveira, A. F., Benetti, J. E., \& Varela, P. S. (2011). Disclosure das Provisões e Dos Passivos e Ativos Contingentes: Um Estudo em Empresas Listadas na BM\&FBOVESPA. Anais do Congresso da Associação Nacional dos Programas de Pós-Graduação em Ciências Contábeis, Vitória, ES, Brasil, 5.

Pereira, A. G., Bruni, A. L., \& Dias, J. M., Filho (2010). Legitimidade Corporativa em Empresas Pertencentes a Indústrias Ambientalmente Sensíveis: Um Estudo Empírico com Empresas que Negociam Ações na Bovespa. Sociedade, Contabilidade e Gestão, 5(2), 69-86.

Porter, M. E. (1991). America's Green Strategy. Scientific American, 264(4), 96. 
Porter, M. E. \& Van Der Linde, C. (1995). Toward a new conception of the environment competitiveness relationship. Jornal of Economic Perspectives, 9(4), 97-118.

Roque, V. \& Cortez, M. C. (2006). A divulgação de informação ambiental e a performance das empresas financeiras cotadas em Portugal. Revista de Estudos Politécnicos, 3(5-6), 119143.

Rufino, M. A. \& Machado, M. R. (2015). Fatores Determinantes da Divulgação de Informações Voluntária Social: Evidências Empíricas no Brasil. Revista de Educação e Pesquisa em Contabilidade - REPEC, 9(4), 380-396.

Rufino, M. A. \& Monte, P. A. (2014). Fatores que Explicam a Divulgação Voluntária das 100 Empresas com Ações Mais Negociadas na BM\&FBOVESPA. Sociedade, Contabilidade e Gestão, 9(3), 59-75.

Santos, L. M. S. (2016). Fatores explicativos da evidenciação de informações ambientais das empresas potencialmente poluidoras listadas na BM\&FBovespa. Dissertação de Mestrado em Ciências Contábeis, Universidade Federal da Paraíba, João Pessoa, PB, Brasil.

Santos, L. M. S., Araújo, R. A. M., \& Leite, P. A. M., Filho (2016). Divulgação voluntária e o valor de mercado: um estudo nas empresas brasileiras de construção civil listadas na BM\&FBovespa. Anais do Congresso Anpcont, Ribeirão Preto, SP, Brasil, 10.

Santos, L. M. S., Lucena, W. G. L., \& Duarte, F. C. L. (2015). Disclosure Voluntário de Informações Sociais: Um Estudo com as Empresas da Construção Civil Listadas na BM\&FBOVESPA. Anais do Congresso Brasileiro de Custos, Foz do Iguaçu, PR, Brasil, 12.

Silva, M. N., Alexandre, J., Freitas, M. A. L., \& Silva, L. L. S., Filho (2014). Determinantes do Disclosure Ambiental nos Relatórios de Empresas Listadas na BM\&FBOVESPA. Anais do Congresso USP de Controladoria e Contabilidade, São Paulo, SP, Brasil, 14.

Sousa, C. B., Silva, A. F., Ribeiro, M. S., \& Weffort, E. F. J. (2014). Valor de mercado e disclosure voluntário: estudo empírico em companhias listadas na BM\&FBOVESPA. Revista Ambiente Contábil, 6(2), 94-115.

Souza, M. A., Rásia, K. A., \& Jacques, F. V. (2010). Evidenciação de informações ambientais pelas empresas integrantes do índice de sustentabilidade empresarial - ISE. Rev. Cont. e Controladoria, 2(1), 75-139.

Stanwick, P. A. \& Stanwick, S. D. (1998). The Relationship Between Corporate Social Performance and Size, Financial and Environmental Performance. Journal of Business Ethics, 17(2), 195-204.

Stulz, R. M. (1990). Managerial Discretion and Optimal Financing Policies. Journal of Financial Economics, 26, 3-27, 1990.

Suave, R, Codesso, M. M., Pinto, H. M., Vicente, E. F. R., \& Lunkes, R. J. (2013). Divulgação de Passivos Contingentes nas empresas mais líquidas da BM\&FBovespa. Revista da UNIFEBE, 1(11), 1-17.

Uyar, A. \& Kiliç, M. (2012). Value relevance of voluntary disclosure: evidence from Turkish firms. Journal of Intellectual Capital, 13(3), 363-376.

Verrecchia, R. (2001). Essays on disclosure. Journal of Accounting and Economics, 32, 97-180. 
Vieira, C. A. M., Arruda, M. P., \& Lima, R. J. V. S. (2014). Custos ambientais de acordo com o potencial impacto poluidor listado pela lei no 10.165/2000: empresas potencialmente mais poluidoras têm mais gastos relacionados ao meio ambiente? Anais do Congresso Brasileiro de Custos, Natal, RN, Brasil, 11. 